\title{
Unavoidable front contact model of Si solar cell through a generalized effective medium approximation approach
}

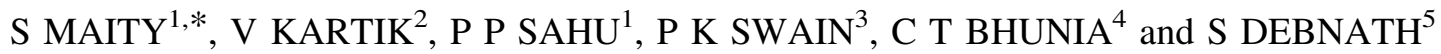 \\ ${ }^{1}$ Electronics and Communication Engineering, Tezpur University, Tezpur 784028, India \\ ${ }^{2}$ Department of Mechanical Engineering, Indian Institute of Technology Bombay, Powai, Mumbai 400076, \\ India \\ ${ }^{3}$ Department of Basic Science, National Institute of Technology, Arunachal Pradesh, Naharlagun 791112, India \\ ${ }^{4}$ Electronics and Communication Engineering, National Institute of Technology, Arunachal Pradesh, \\ Naharlagun 791112, India \\ ${ }^{5}$ Department of Information Technology, Mizoram University, Tanhril, Mizoram 796004, India \\ e-mail: santanu.ece@nitap.in
}

MS received 3 January 2015; revised 23 February 2017; accepted 19 September 2017; published online 14 March 2018

\begin{abstract}
Fill factor of the solar cell mainly depends on series resistance and contact resistance, which are the most effective parameters to collect carriers (electrons and holes) from both electrodes of C-Si solar cells. We have used both mathematical and experimental approaches to reduce these resistances for enhancement of power conversion efficiency (PCE) by increasing fill factor. After processing by light-induced plating (LIP) for metal contact, the PCE of solar cell is obtained as $14.43 \%$, which is $8.8 \%$ more than that before LIP processing.
\end{abstract}

Keywords. Contact resistance; quantum efficiency; series resistance; GEMA; void fraction; LIP.

\section{Introduction}

The development of pores/voids during deposition of contact paste at higher temperature by screen printing process, leading to higher contact resistance and series resistance, causes degradation of power conversion efficiency (PCE) of solar cell. The improvement of solar cell resistive performance has been discussed in many literatures [1-13]. Low cost silver $(\mathrm{Ag})$ paste screen-printing method has emerged as the dominant technology for front-side metallization of silicon $(\mathrm{Si})$ solar cells. Later, different technologies such as laser doping [14-17], self-aligning technology and screen printing, and lithography have been reported to reduce these resistances for enhancement of PCE. Recently, light-induced electroplating has been used for making front contact with silver as a low-cost promising method to improve fill factor of the solar cell [18-21]; Jensen et al 1979).

In this article, we have developed a mathematical modelling of series resistance of front side contact made through by considering uniformly and non-uniformly distributed pores in both finger and bus bar of solar cells. The generalized effective medium approximation (GEMA) is applied for distributed voids of different shapes and sizes. Light-induced plating (LIP) was used for making metallic contact of the solar cell to reduce these resistances. The

*For correspondence plasmonic effect observed in LIP leads to the increase of short circuit current density and quantum efficiency in solar cell.

\section{Mathematical modelling of metallic resistance with respect to void parameters}

During fabrication of metallic contact on solar cells, pores/ voids are formed on the metallic contact. The effect on series resistance of void sizes should be analysed as the performance of solar cell such as PCE and fill factor depends on series resistance directly. We consider a metallic bar contact having a single void of length $l_{o}$ and width $w$ as a finger of length $l$ as shown in figure 1. Keeping the length of void fixed, the void size is reduced from $l_{0} w$ to $l_{0} w_{0}$ to obtain more contact area (figure 2). The effective resistance of this corresponding model is written as

$$
\begin{aligned}
R & =\rho \frac{l-l_{o}}{w t}+\rho \frac{l_{o}}{\left(w-w_{0}\right) t} \\
& =\frac{\rho}{t}\left(\frac{l-l_{o}}{w}+\frac{l_{o}}{\left(w-w_{0}\right)}\right)
\end{aligned}
$$

where $w, t, \rho$ and $R$ are the width, thickness, resistivity and total resistance of the bar, respectively; $w_{0}$ is the width of the pore. 


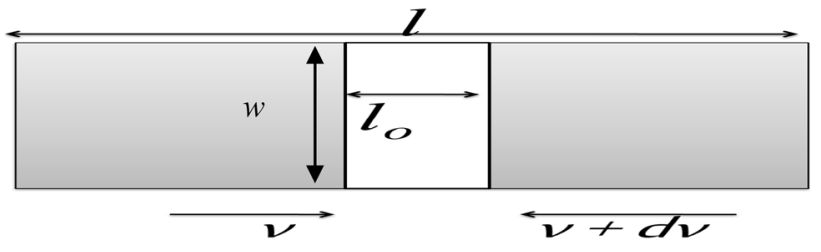

Figure 1. Finger (metallic bar) with single void of length $l_{o}$.

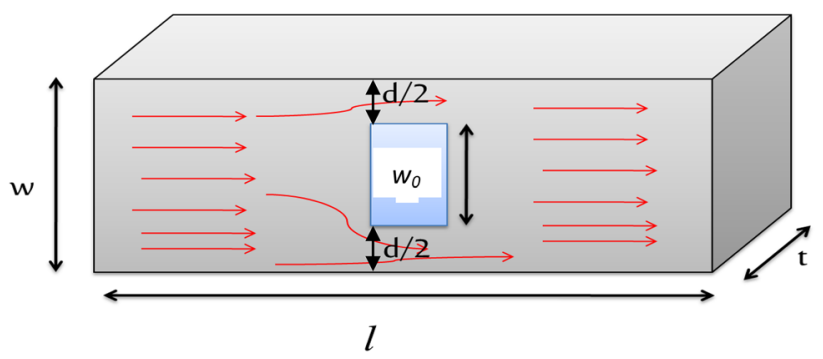

Figure 2. Width of the void decreases to $w_{0}$ such that $w=w_{0}+d$.

We have assumed that there are $m n$ number of voids in the metal bar and distributed uniformly throughout the bar as shown in figure 3 and all the voids are rectangular in shape and of same size (where $l_{0}, t$ and $w_{0}$ are length, thickness and width of the single void, respectively). The corresponding resistance in this model is written as

$$
\begin{gathered}
R=\frac{\rho}{w t\left(w-n w_{o}\right)}\left(l w-m l_{o} w-n l w_{o}+m n w_{o} l_{o}+m l_{o} w\right), \\
R=\frac{\rho}{w t\left(w-n w_{o}\right)}\left[l w-n l w_{o}+V_{\text {grid }} l w\right] .
\end{gathered}
$$

Equation (3) is simplified to Eq. (4). All the voids of metal bar are represented by voids fraction $\left(V_{\text {grid }}\right)$, which

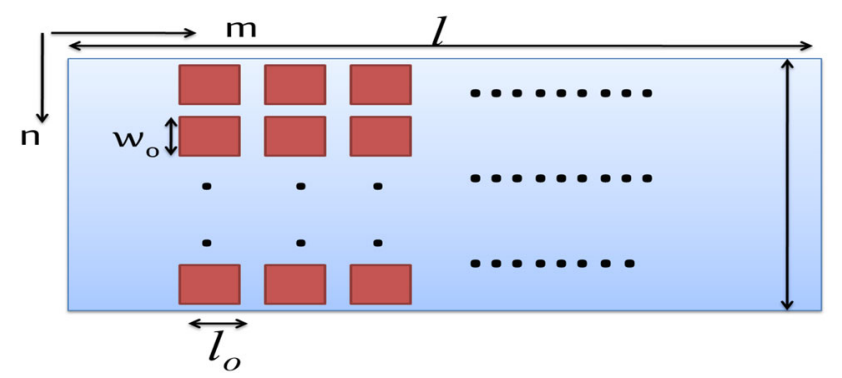

Figure 3. Voids are distributed throughout the finger bar; $m$ number of voids are distributed throughout the length of the bar and $n$ number of voids are distributed throughout the width of the bar (uniform distribution). can be expressed as $V_{\text {grid }}=\frac{\left(m l_{o}\right)\left(n w_{o}\right) t}{l w t}$. Equation (4) is further written in terms voids fraction $\left(V_{\text {grid }}\right)$ as

$$
R=R_{o}\left[1+V_{\text {grid }} \frac{w}{\left(w-n w_{o}\right)}\right]
$$

It is seen from Eq. (5) that series resistance increases with increase of void numbers due to the increase of void fraction. In fact, voids obtained during deposition of metal contact are of an arbitrary rectangular shape and considering arbitrary shape of voids, the effective series resistance is written as

$$
R_{\text {eff }}=\rho\left(\frac{L}{w . t}\right)\left[1+\frac{f_{v}}{1-\frac{\Delta L}{t}}\right]
$$

where $f_{v}$ is void fraction, $w$ is width of the bar and $\Delta L$ is size of the void. The variations of effective series resistance with change of different finger parameters such as width of the finger, diameter of the pore and void (pore) fraction using Eq. (6) are shown in figure 4. Figure 4a shows that effective resistance decreases as width of the finger increases and decreases slowly after $1.4 \times 10^{-4} \mathrm{~m}$ whereas figure $4 \mathrm{~b}$ shows that effective resistance increases with increase of void fraction. Figure $4 c$ depicts that effective resistance increases with increase of void fraction. Finally, fill factor is affected with increase of series resistance as shown in figure $4 \mathrm{~d}$. The fill factor decreases with increase of series resistance due to lesser carrier collection efficiency. Hence, enhancement of fill factor requires the decrease of series resistance, for which void fraction should be kept as minimum as possible, width of finger should be as large as possible (in the range of $1.4 \times 10^{-4}-1.5 \times 10^{-4} \mathrm{~m}$ (figure $4 \mathrm{a}$ ) and width of void should be in the range of $1 \times 10^{-4}-4 \times 10^{-4} \mathrm{~cm}$ (figure $4 b$ ).

The non-uniform distribution of voids (any shape) is then studied by GEMA approach. The corresponding field lines are shown in figure 5a. The GEMA condition is written as

$$
V_{\text {air }} \frac{\sigma_{\text {air }}-\sigma_{e}}{\sigma_{\text {air }}-2 \sigma_{e}}+\left(1-V_{\text {air }}\right) \frac{\sigma_{\text {metal }}-\sigma_{e}}{\sigma_{\text {metal }}-2 \sigma_{e}}=0
$$

After simplification, we can rewrite Eq. (7) as

$$
\frac{\sigma_{\text {metal }}-\sigma_{e}}{\sigma_{\text {metal }}-2 \sigma_{e}}+\frac{1}{2}=V_{\text {air }}\left[\frac{\sigma_{\text {metal }}-\sigma_{e}}{\sigma_{\text {metal }}-2 \sigma_{e}}+\frac{1}{2}\right]
$$

where $\sigma_{\text {air }}$ is conductivity due to air portion, $\sigma_{e}$ is effective conductivity and $\sigma_{\text {metal }}$ is conductivity of the metal portion. If $V_{\text {air }}=0$ then $\sigma_{e}=\sigma_{\text {metal }}$ and also if $V_{\text {air }}=1$ then $\sigma_{e}=\sigma_{\text {air }}$; as $\sigma_{\text {air }} \rightarrow 0$, Eq. (8) is written, considering Ohm's law, as

$$
R=\rho \frac{l}{A}=\frac{1}{\sigma_{\text {metal }}\left(1-3 V_{\text {air }}\right)} \frac{l}{A}
$$



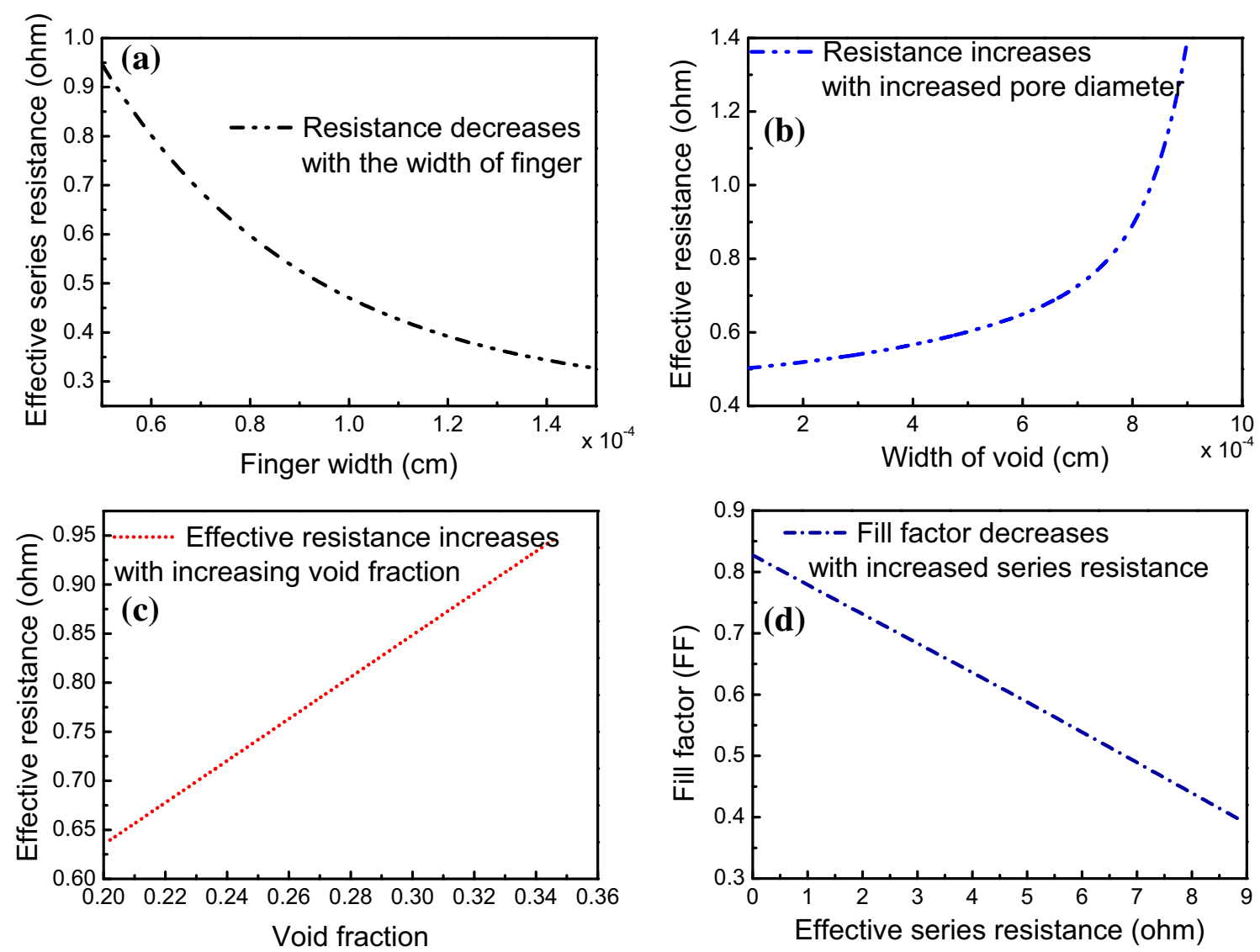

Figure 4. Variation of effective series resistance with change of void parameters: (a) effective resistance vs width of the finger, (b) effective resistance vs width of void, (c) effective resistance vs void fraction and (d) fill factor vs effective series resistance.
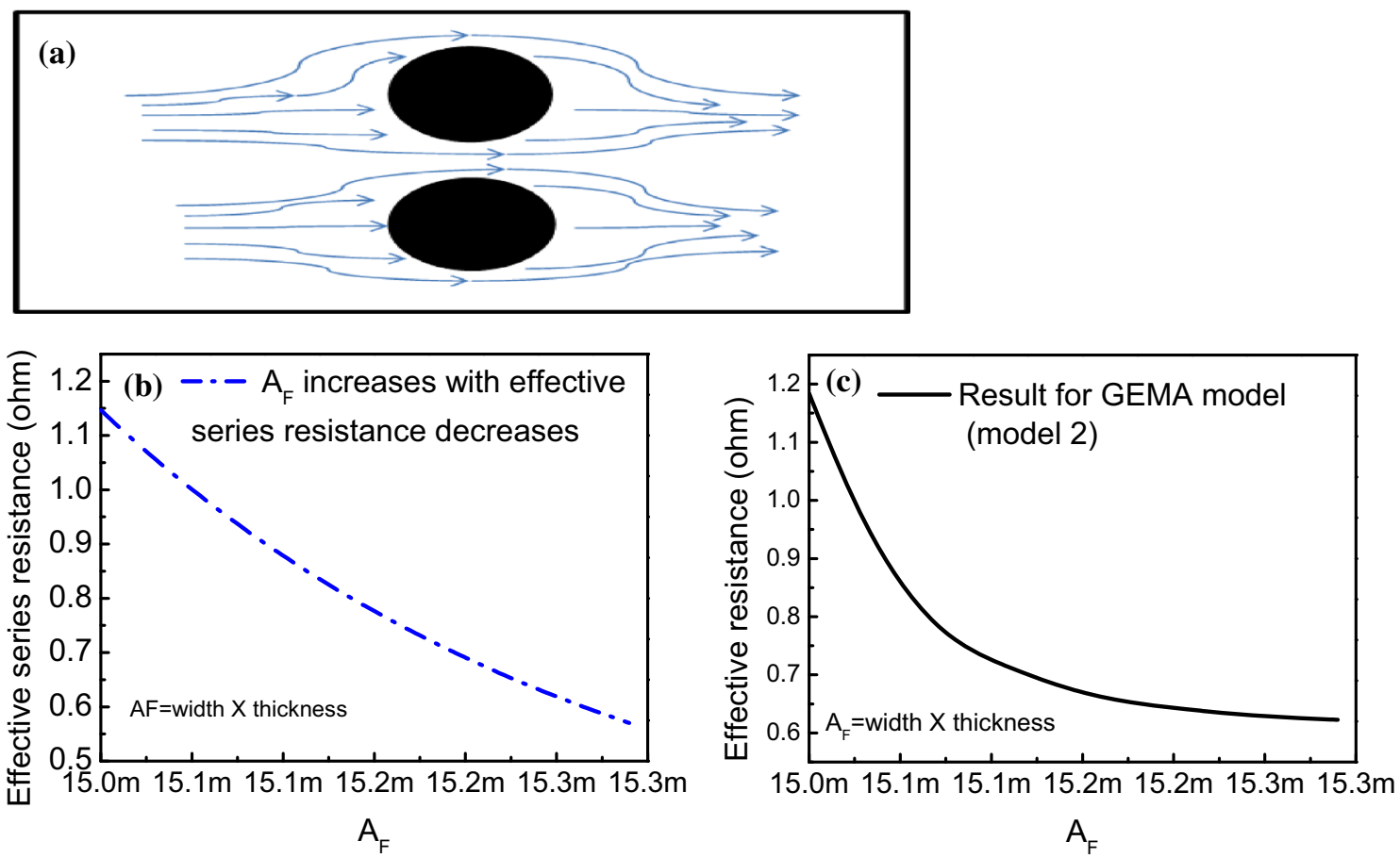

Figure 5. (a) Non-uniformly distributed spherical voids are in the finger with the effective field line. (b) Effective resistance vs crosssectional area $\left(A_{F}=\right.$ width $\times$ thickness) of finger derived using Eq. (6) without GEMA approach. (c) Effective resistance vs crosssectional area of finger derived with GEMA approach. 


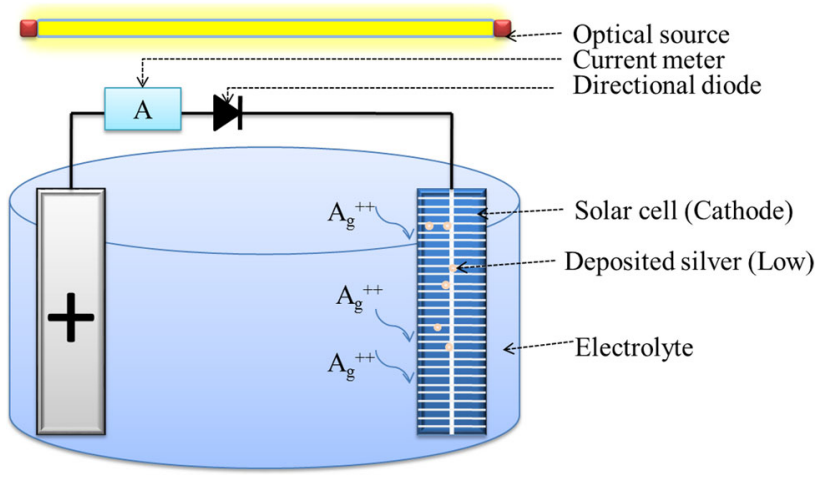

Figure 6. Schematic representation of light-induced plating with suitable optical arrangement.

It is seen that resistance expression following Ohm's law is a function of effective conductivity of metal, void fraction, length and width of the bar. Figure $5 \mathrm{~b}$ shows the variation of effective series resistance with cross-sectional area of finger $\left(A_{F}\right)$ obtained using Eq. (6) without GEMA approach whereas figure $5 \mathrm{c}$ presents the variation of effective series resistance with cross-sectional area of finger obtained using Eq. (9) with GEMA approach. In both approaches, effective series resistance decreases with $A_{F}$. The GEMA approach is closer to the experimental results as shown later in the paper.

\section{Experimental verification}

The control of series resistance by changing processing parameters was shown experimentally. At the time of firing during screen printing, the unwanted pores on the front contact are formed due to the evaporation of silver paste, which in turn decreases the efficiency of solar cell due to increase of series resistance. LIP is an attractive method to reduce contact resistance and improve fill factor as distribution of voids and size can be controlled. The LIP experimental set-up is shown in figure 6 .

A suitable silver potassium cyanide solution was chosen as an electrolyte, silver plate as anode and solar cell as cathode. No external bias set-up was added for experimental purpose because the light source activated the solar cell for electroplating. After the LIP process the pores/voids get filled with silver particles and it reduces number of voids and controls the size of voids along with their distribution (as evident from figure $7 \mathrm{a}$ and $\mathrm{b}$ ), leading to the reduction of series resistance.

Two different parameters (solution concentration and light intensity) were optimized for LIP treatment. It was observed that the decrease of series resistance for $660 \mathrm{~W} /$ $\mathrm{m}^{2}$ light intensity is more than that for $330 \mathrm{~W} / \mathrm{m}^{2}$ because deposition of silver particles is more at $660 \mathrm{~W} / \mathrm{m}^{2}$ light intensity as shown in figure 8 .

At the same time, it was also seen that the decease of series resistance is more for $15 \mathrm{~g} / \mathrm{l}$ electrolyte solution than that for 12.5 and $5 \mathrm{~g} / \mathrm{l}$ electrolyte solutions, as shown in figure 9.

After the LIP experiment, it is seen that pores are filled up by the deposited silver, as the area of the finger increases and resistance decreases. The series resistance vs $A_{F}$ (figure 10) obtained experimentally is very close to that by the GEMA model as shown in figure $5 \mathrm{c}$. Thus, after treatment of LIP the series resistance is reduced, leading to improvement of solar cell performance.

In the LIP process, electrolytes penetrated the holes in the glass frit layer and the plated silver contact was made with idle silver crystals and high silver crystal density. During LIP, sufficient amount of high-density silver crystals was formed during the firing process. Figure 11 shows that the short circuited current is enhanced from 0.15 to

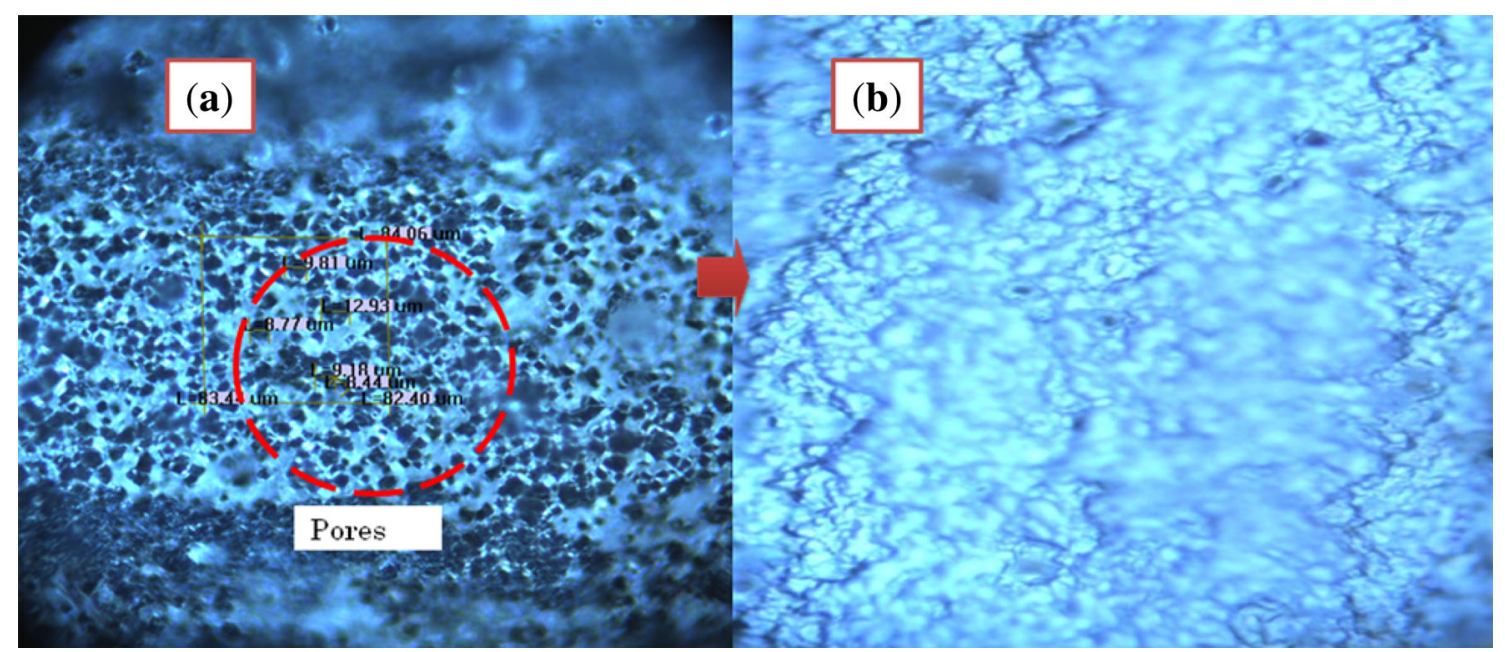

Figure 7. Optical microscopic view of solar cell contact before and after LIP treatments: (a) microphotograph of finger before LIP $(100 \times)$ and $(\mathbf{b})$ microphotograph of finger after LIP $(100 \times)$. 


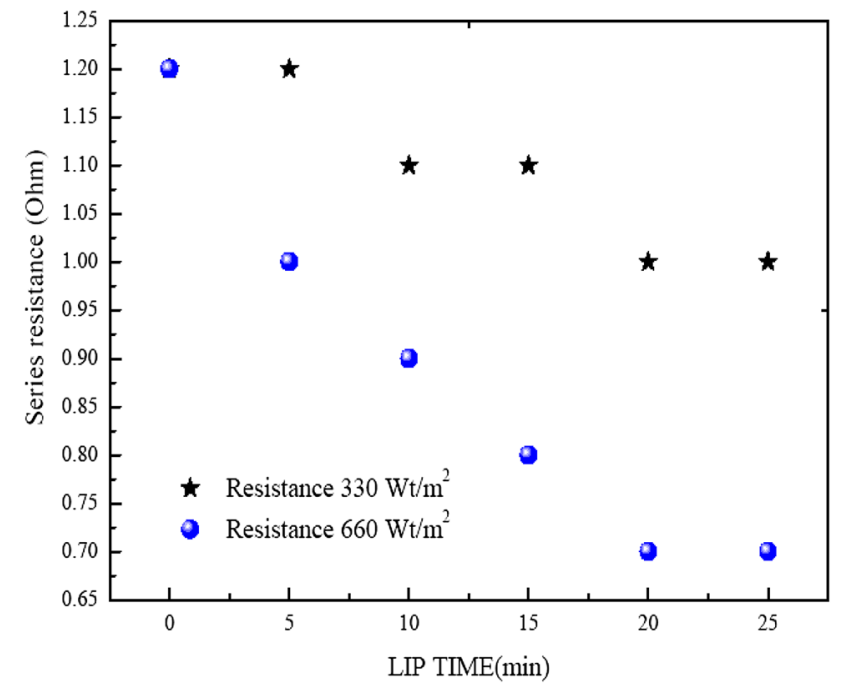

Figure 8. Change of series resistance with respect two different light intensities: 330 and $660 \mathrm{~W} / \mathrm{m}^{2}$.

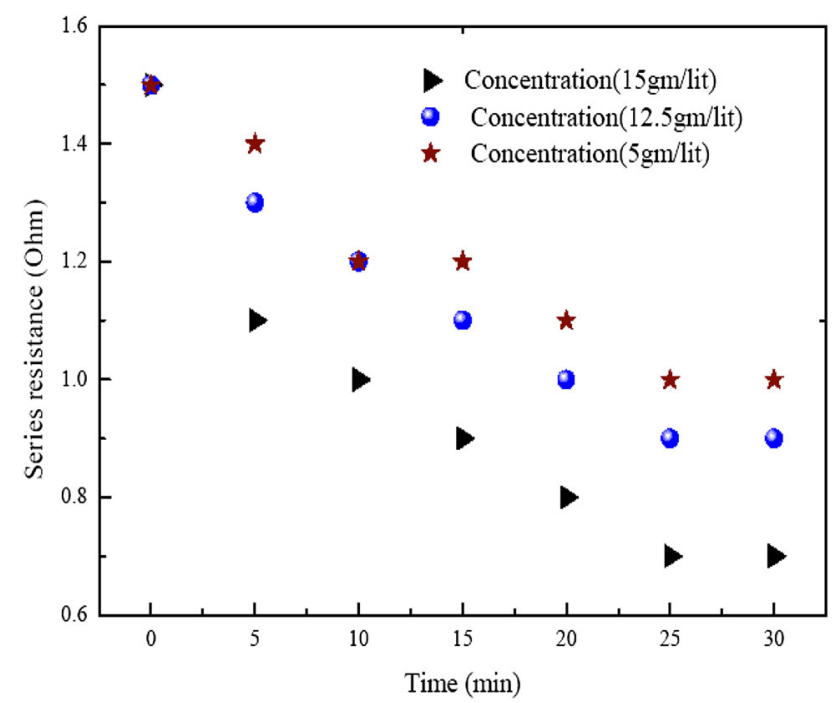

Figure 9. Change of series resistance with respect to time at three different solution concentrations: 5, 12.5 and $15 \mathrm{~g} / \mathrm{l}$.

0.162 A due to silver nanoparticle deposition on the solar cell. Deposited silver nanoparticles on the top surface of the solar cell introduce a plasmonic effect, which enhances quantum efficiency of the solar cell as shown in figure 12 . Metallic nanoparticles (silver, gold) show most interesting properties in the presence of strong absorption and scattering in the visible region [22]. These properties are the result of localized surface plasmon resonance (LSPR), a collective oscillation of the surface electrons that occurs when light interacts with a particle at its resonant frequency. A schematic representation of plasmonic effect is shown in figure 13. The PCE after LIP treatment is enhanced from $13.26 \%$ to $14.43 \%$ as obtained from figure 11.

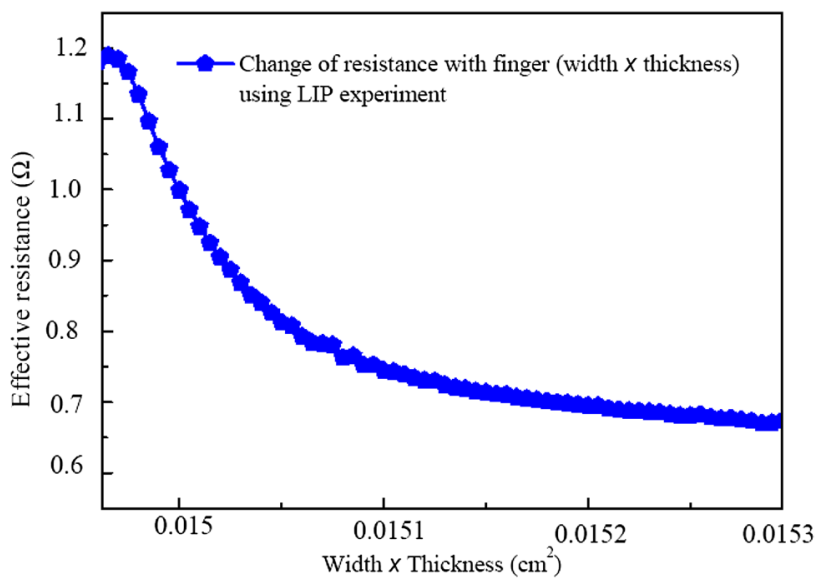

Figure 10. Effective resistance vs $A_{F}$ obtained experimentally after LIP treatment.

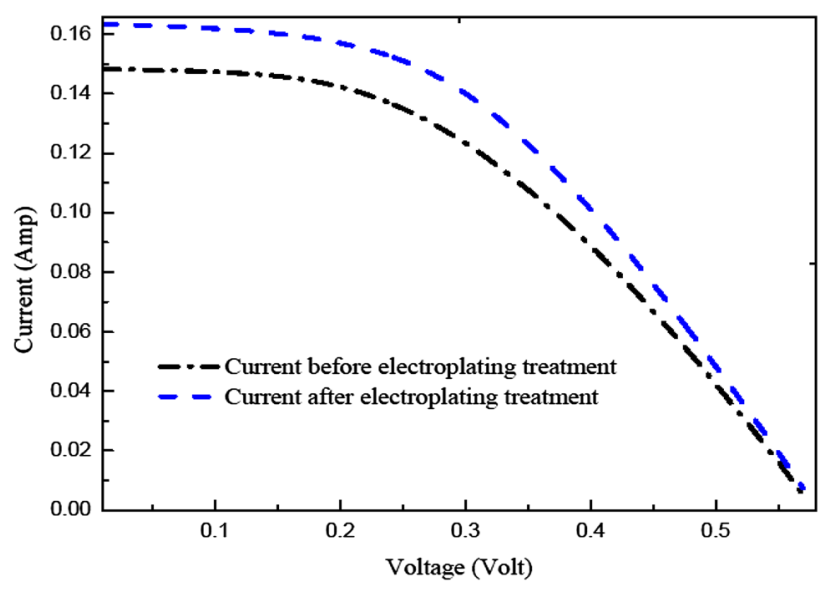

Figure 11. $I-V$ characteristics of solar cell before and after LIP treatment.

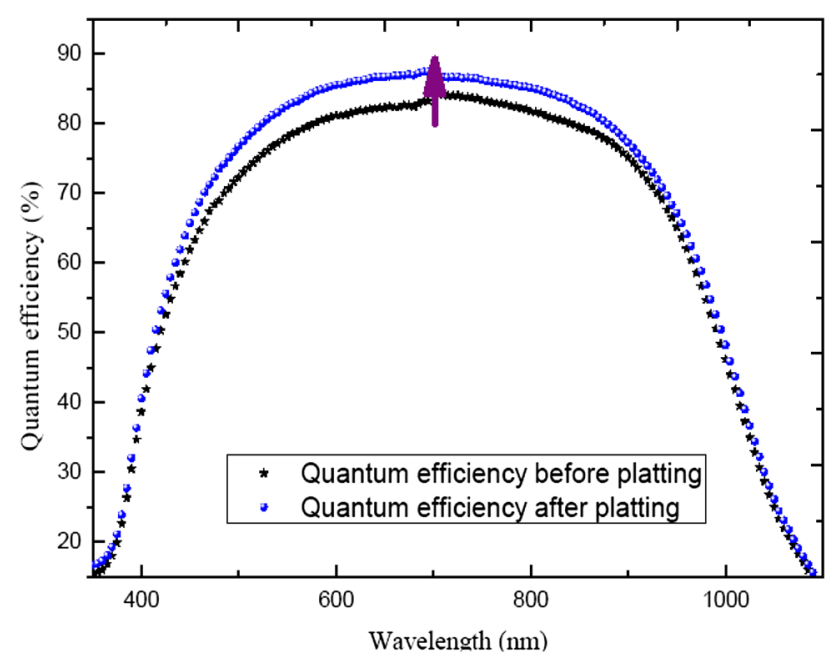

Figure 12. Change of quantum efficiency after LIP treatmentEQE increases. 


\section{Illumination}

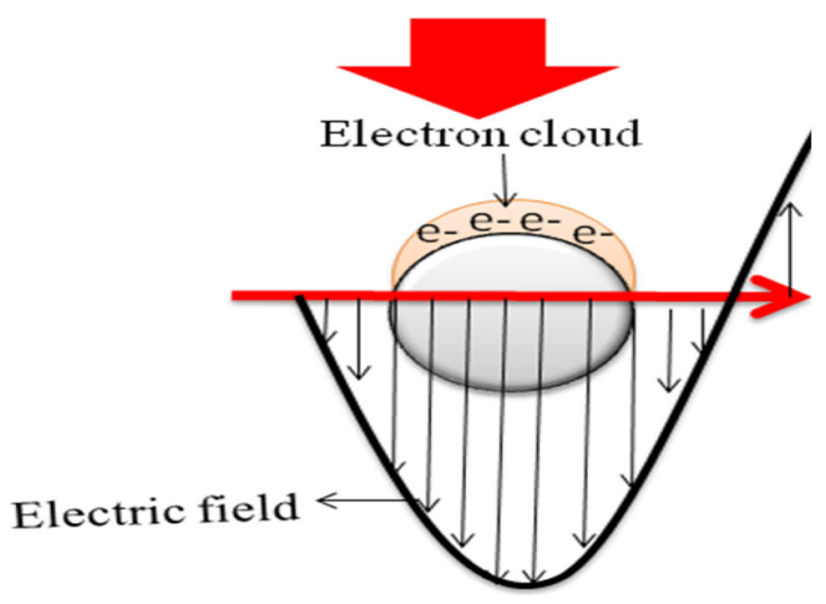

Figure 13. Schematic representation of plasmonic effect.

\section{Conclusion}

In this paper, a mathematical model of series resistance in terms of number of voids and their dimension has been developed. The reduction of series resistance was obtained experimentally after LIP treatment of metallic contact with control of light intensity and concentration of electrolyte. It is found that the series resistance significantly reduces at $660 \mathrm{~W} / \mathrm{m}^{2}$ light intensity and $15 \mathrm{~g} / \mathrm{l}$ electrolyte concentration. On controlling LIP process parameters, reduction of series resistance leads to enhancement of quantum efficiency and it ultimately improves fill factor of the solar cell. The PCE after LIP treatment is enhanced from $13.26 \%$ to $14.43 \%$ after LIP processing.

\section{References}

[1] Araujo G L and Sanchez E 1982 A new method for experimental determination of the series resistance of a solar cell. IEEE Trans. Electron. Dev. 29: 1511-1513

[2] Chegaar M, Nehaoua N and Bouhemadou A 2008 Organic and inorganic solar cells parameters evaluation from single I-V plot. Energy Convers. Manage. 49: 1376-1379

[3] Chegaar M, Ouennoughi Z and Hoffmann A 2001 A new method for evaluating illuminated solar cell parameters. Solid-State Electron. 45: 293-296

[4] Easwarakhanthan T, Bottin J, Bouhouch I and Boutrit C 1986 Nonlinear minimization algorithm for determining the solar cell parameters with microcomputers. Int. J. Sol. Energy 4: $1-12$

[5] Handy R J 1967 Theoretical analysis of the series resistance of a solar cell. Solid-State Electron. 10: 765-775

[6] Ishibashi K I, Kimura Y and Niwamo M 2008 An extensively valid and stable method for derivation of all parameters of a solar cell from a single current-voltage characteristic. $J$. Appl. Phys. 103: 094507
[7] Jain A and Kapoor A 2005 A new approach to study organic solar cell using Lambert W-function. Sol. Energy Mater. Sol. Cells 86: 197-205

[8] Kaminski A, Marchand J J and Laugier A 1999 I-V methods to extract junction parameters with special emphasis on low series resistance. Solid-State Electron. 43: 741-745

[9] Murayama M and Mori T 2006 Equivalent circuit analysis of dye-sensitized solar cell by using one-diode model: effect of carboxylic acid treatment of $\mathrm{TiO}_{2}$ electrode. Jpn. J. Appl. Phys. 45(pt1): 542-545

[10] Ortiz-Conde A, Sánchez F J G and Muci J 2006 New methods to extract model parameters of solar cells from the explicit analytic solutions of their illuminated I-V characteristics. Sol. Energy Mater. Sol. Cells 90: 352-361

[11] Radziemska E 2005 Dark I-U-T measurements of single crystalline silicon solar cells. Energy Convers. Manage. 46: 1485-1494

[12] Rajkanan K and Shewchun J 1979 A better approach to the evaluation of the series resistance of solar cells. Solid-State Electron. 22: 193-197

[13] Wolf M and Rauschenbach H 1963 Series resistance effects on solar cells measurements. Adv. Energy Convers. 3: 455-479

[14] Kray D, Bay N, Cimiotti G, Kleinschmidt S, Kösterke N, Lösel A, Sailer M, Träger A, Kühnlein H, Nussbaumer H, Fleischman C and Granek F 2010 Industrial LCP selective emitter solar cells with plated contacts. In: Proceedings of the 35th IEEE Photovoltaic Specialists Conference, June 20-25, pp. 667-671

[15] Mai L, Hameiri Z, Tjahjono B S, Wenham S R, Sugianto A and Edwards M B 2009 Rear junction laser doped solar cells on CZ n-Type silicon. In: Proceedings of the 34th IEEE Photovoltaic Specialists Conference, Philadelphia, June 7-12, pp. 1811-1815

[16] Sugianto A, Bovatsek J, Wenham S, Tjahjono B, Xu G, Yao Y, Hallam B, Bai X, Kuepper N, Chong C M and Patel R 2010 18.5\% laser-doped solar cell on CZ p-type silicon. In: Proceedings of the 35th IEEE Photovoltaic Specialists Conference, June 20-25, pp. 689-694

[17] Tjahjono B S, Guo J H, Hameiri Z, Mai L, Sugianto A, Wang S and Wenham S R 2007 High efficiency solar cell structure through the use of laser doping. In: Proceedings of the 22nd European Photovoltaic Solar Energy Conference, September 3-7, pp. 966-969

[18] Glunz S W 2007 High-efficiency crystalline silicon solar cells. Adv. Opto-Electron. 2007: 15, Article ID 97370

[19] Mette A, Schetter C, Wissen D, Lust S, Glunz S W and Willeke G 2006 Increasing the efficiency of screenprinted silicon solar cells by light induced silver plating. In: Proceedings of the $4^{\text {th }}$ IEEE World Conference on Photovoltaic Energy Conversion, Hawaii, USA, May, pp. 1056-1059

[20] Durkee L F 1979 US Patent No. 4144139. Solarex Corporation, USA

[21] Jensen J D, Møller P, Bruton T, Mason N, Russell R, Hadley J, Verhoeven P and Matthewson A 2003 Electrochemical deposition of buried contacts in high-efficiency crystalline silicon photovoltaic cells. J. Electrochem. Soc. 150: G49-G57

[22] Vincenzo A, Bakr O M and Stellacci F 2010 A study of the surface plasmon resonance of silver nanoparticles by the discrete dipole approximation method: effect of shape, size, structure, and assembly. Plasmonics 5(1): 85-97 